\title{
A SEMI-AUTOMATIC CROPLAND MAPPING APPROACH USING GEOBIA AND RANDOM FORESTS ON BLACK-AND-WHITE AERIAL PHOTOGRAPHY
}

\author{
M. F. A. Vogels ${ }^{a}, *$, S. M. de Jong ${ }^{\text {a }}$, G. Sterk ${ }^{\text {a }}$, E. A. Addink ${ }^{\text {a }}$ \\ ${ }^{\text {a }}$ Utrecht University, Department of Physical Geography, PO box 80115, 3508 TC Utrecht, The Netherlands - (M.F.A.Vogels, \\ S.M.deJong, G.Sterk, E.A.Addink)@uu.nl
}

KEY WORDS: Agricultural cropland expansion, land-use change, black-and-white (historical) aerial photography, GEOBIA, Random Forests

\begin{abstract}
:
For decades land-use and land-cover (LULC) conversions have had an important impact on land- and ecosystem degradation, accordingly (historical) LULC information is important for the assessment of such impacts. This information can be derived from black-and-white (B\&W) aerial photography. Such photography is often visually interpreted, which is a very time-consuming approach. This study shows that machine learning can be applied on only brightness to derive LULC information. Cropland acreage is semi-automatically mapped by means of Geographic Object-Based Image Analysis (GEOBIA) and Random Forest classification in two study sites in Ethiopia and in The Netherlands. The result is a thematic map with two classes: 1) agricultural cropland and 2) other types of land cover. Overall mapping accuracies attained are $90 \%$ and $96 \%$ for the two study areas respectively. This mapping method increases the timeline at which historical cropland expansion can be mapped purely from brightness information in B\&W photography up to the 1930s.
\end{abstract}

\section{INTRODUCTION}

During the past decades major LULC conversions occurred in Africa, Southeast Asia and South America as a consequence of a growing population and economy. Most dominant is the conversion of natural vegetation into agriculture. Unsustainable management practices in the agricultural sector are seen as the major driver of land degradation (Foley et al., 2005), which poses a threat for food security, biodiversity, biomass productivity and environmental sustainability (Millennium Ecosystem Assessment 2005; Mueller et al., 2014).

Historical land-use (change) maps are important information in the assessment of LULC change on land- and ecosystem degradation. This can be derived from $\mathrm{B} \& \mathrm{~W}$ aerial photography. The use of such photography is limited due to its panchromatic spectral information. An image analyst can visually identify cropland plots in B\&W aerial photography by the cropland plot's characteristic rectangular shape, and smooth, regular texture, but such imagery holds little information for machine learning.

This study has developed a semi-automated procedure to map cropland acreage in B\&W photography using GEOBIA and Random Forest classification. To assess the universal applicability of this mapping approach, the method is tested and validated in two contrasting study areas with respect to LULC types: 1) the Awassa Lake region in the Central Rift Valley in Ethiopia and 2) the Bladel Kempen region in the Netherlands.

\section{METHODOLOGY}

\subsection{Data description}

B\&W aerial photography was simulated from the Web Map Service layer named World Imagery (ESRI, 2015). The methodology was evaluated on 15 sectors for each region comprising a variety of LULC. For the Awassa Lake region panchromatic imagery from WorldView-1 (0.5 m spatial resolution) was used. For the Bladel Kempen region aerial data (average of three bands: $400-700 \mathrm{~nm}$ ) from the UltraCam-G camera ( $0.3 \mathrm{~m}$ spatial resolution) was used. The slope is added as a covariate for the classification of cropland.

\subsection{Workflow}

Four stages were involved in this mapping procedure: 1) the original $\mathrm{B} \& \mathrm{~W}$ photograph was segmented into coherent landscape elements (objects), e.g. cropland plots, 2) a training and validation set were generated by means of interpretation of B\&W photography and ancillary data sources by randomly selecting a number of objects, 3) these landscape objects were then classified by a Random-Forest algorithm into either 'cropland' or 'other land cover', on the basis of object attributes including textural, shape, slope, neighbour and spectral variables (the 'other land cover' class incorporates all other LULC), and 4) accuracy statistics of this classification procedure were calculated to validate the method.

\section{RESULTS AND DISCUSSION}

\subsection{Classification performance}

Cropland classification in the Awassa Lake region and the Bladel Kempen region have an overall accuracy and kappa coefficient of $90 \%$ and 0.77 and $96 \%$ and 0.91 respectively. Two sectors in the Awassa Lake region show significant swamp land cover in the B\&W photography, but this is not well depicted in the LULC maps where it is miss-classified as cropland. Also in the Bladel Kempen region classification proves to be more difficult in large natural vegetated area's.

\footnotetext{
* Corresponding author
} 
Here a small number of objects; $0.8 \%$ and $6.8 \%$ of the objects in two sectors, are wrongly classified as cropland.

\subsection{Classification uncertainty}

Historical aerial photography is subject to common issues such as light falloff, distortion and image noise (Aber et al., 2010; Morgan et al., 2010). Differences in Field of View and time of day will not be consistent over time and space and information to correct for those absent. This is a source of uncertainty that cannot be quantified and may influence the segmentation results, the training- and validation set generation and, hence classification performance. The high performance of this methodology on imagery from Web Map Service layers in this study highlights the even higher potential when applied on actual aerial photography, which generally have a higher radiometric resolution and therefore hold more information for the distinction of landscape elements.

\section{CONCLUSIONS}

The classification procedure shows good results throughout the two study areas. It proved more difficult to classify objects in dense homogeneous natural vegetated areas, where some objects were confused with cropland. A solution was found by adding slope as an additional variable. The application of the method in the two study area's is assumed to cover a wide range of current landscape patterns and LULC globally, making the method portable to other regions. It provides valuable information on LULC change, which is important to assess the impacts of land-cover change on land- and ecosystem degradation processes such as runoff, erosion, and water availability. The method is fast and efficient in mapping the expansion or shrinking of cropland acreage at the regional scale wherever historical B\&W aerial photography is available, which is especially valuable for regions where historical land-use statistics are mostly absent.

\section{ACKNOWLEDGEMENTS (OPTIONAL)}

This study is funded by Climate-KIC (Task ID: ARED0004_2013-1.1-008_P001-06).

\section{REFERENCES}

Aber, J. S., Marzolff, I., Ries, J., 2010. Small-format aerial photography: principles, techniques and geoscience applications, 1st Edition. Elsevier, Amserdam, Oxford, p. 76.

ESRI, 2015. ArcGIS Online Standard Service: World Imagery Collection, Map Server. Maps throughout this book were created using $\operatorname{ArcGIS}^{\circledR}$ software by ESRI. ArcGIS ${ }^{\circledR}$ and ArcMap $^{\mathrm{TM}}$ are the intellectual property of ESRI and are used herein under license. Copyright ${ }^{\odot}$ ESRI. For more information about ESRI ${ }^{\circledR}$ software: www.esri.com, Accessed 25 February 2015.

Foley, J. A., Defries, R., Asner, G. P., Barford, C., Bonan, G., Carpenter, S. R., Chapin, F. S., Coe, M. T., Daily, G. C., Gibbs, H. K., Helkowski, J. H., Holloway, T., Howard, E. A., Kucharik, C. J., Monfreda, C., Patz, J. A., Prentice, I. C., Ramankutty, N., Snyder, P. K., 2005. Global consequences of land use. Science, 309, pp. 570-574.

Millennium Ecosystem Assessment, 2005. Ecosystems and human well-being: biodiversity synthesis. Tech. rep., World Resources Institute, Washington D.C., p. 30.
Morgan, J. L., Gergel, S. E., Coops, N. C., 2010. Aerial photography: a rapidly evolving tool for ecological management. BioScience, 60, pp. 47-59.

Mueller, E. N., Wainwright, J., Parsons, A. J., Turnbull, L., 2014. Land degradation in drylands: an ecogeomorphological approach. In: Patterns of land degradation in drylands: understanding self-organised ecogeomorphic systems. Springer, Dordrecht, Heidelberg, New York, London, p. 3. 